Research Article

\title{
Performance of a Large-Scale Excavation by Bottom-Up Technique in Hangzhou Soft Clay
}

\author{
Ri-qing Xu $\mathbb{D}^{1,2}$ Yi-hong Zhu $\mathbb{D}^{1,2}$ and Pan Ding $\mathbb{D}^{1,2}$ \\ ${ }^{1}$ Research Center of Coastal and Urban Geotechnical Engineering of Zhejiang University, Hangzhou 310058, China \\ ${ }^{2}$ Engineering Research Center of Urban Underground Space Development of Zhejiang Province, Hangzhou 310058, China
}

Correspondence should be addressed to Yi-hong Zhu; zjuzhuyihong@zju.edu.cn

Received 9 April 2021; Accepted 20 June 2021; Published 5 July 2021

Academic Editor: Xin-Jiang Wei

Copyright (c) 2021 Ri-qing Xu et al. This is an open access article distributed under the Creative Commons Attribution License, which permits unrestricted use, distribution, and reproduction in any medium, provided the original work is properly cited.

This paper studied the excavation of a foundation pit above a running subway tunnel in Hangzhou soft soil. The zoned excavation and top-down construction techniques were adopted to control the deformation caused by foundation pit excavation. The excavation was divided into four parts, named Zone A, B, C, and D. Zone A adopted temporary diagonal bracing, and the control effect of deformation was poor; it was cancelled and changed to rapid excavation and thicker cushion in Zones B, C, and D. During the whole construction process, the lateral displacement and settlement of the diaphragm wall, surrounding ground surface, and building settlement were monitored and analysed. The data showed that the lateral displacement of the diaphragm wall was effectively reduced by the zoned excavation technique, and the maximum lateral displacement value of the diaphragm wall in Zone A was the least; rapid excavation and reduced soil exposure time also could effectively control the deformation, and the lateral displacement of the diaphragm wall in Zone $\mathrm{C}$ is less than Zone $\mathrm{B}$ and Zone $\mathrm{D}$. The ground settlement is strongly related to the lateral displacement of the diaphragm wall. In order to reduce the surrounding ground and building settlements, efforts should be made to reduce the wall lateral displacement.

\section{Introduction}

In recent years, the scale of Hangzhou has expanded rapidly. The development of underground space will cause the redistribution of soil stress and affect the surrounding environment. Development in the central area of the city will have a greater impact on nearby buildings. In order to make full use of the land resources in the central area of the city, the excavation depth of the foundation pit is large and the scope of influence is wide. With the continuous maturity of engineering technology in our country, the core contradiction of deep foundation pit excavation has gradually changed from the problem of foundation pit safety to the problem of foundation pit deformation control.

Scholars had collected a large number of excavation cases, compared the deformation characteristics of foundation pits under various geological conditions with indicators such as the maximum lateral displacement of the excavation and the maximum ground surface settlement, and then established empirical parameters in different regions for future design practices [1-4]. Some scholars also conducted statistical analysis on regional foundation pits and formed regional indicators; the maximum lateral displacement of the foundation pit in the hard clay soil area collected by Clough [5], Yoo [6], Long [7], etc., was between 0.05 and $0.20 \% H_{e}\left(H_{e}\right.$ was the excavation depth of the foundation pit, omitted later). The maximum lateral displacement of foundation pits in soft soil areas collected by $\mathrm{Ou}$ [8] and Long [7] was between 0.40 and $0.48 \% H_{e}$.

Chinese scholars had also performed the analysis of deformation characteristics of foundation pits. Wang $[9,10]$ conducted a statistical analysis of the deformation of the foundation pit under the condition of deep and soft soil in the Shanghai area. It was found that the average horizontal displacement of foundation pits in the Shanghai area was $0.26-0.50 \% H_{e}$. Tan $[11,12]$ reported a large-scale deep foundation pit in Shanghai, and the maximum lateral 
displacement ranged between $0.35 \% H_{e}$ and $0.55 \% H_{e}$. And, many other cases had also been reported and used in foundation pit deformation analysis $[13,14]$.

This project was located in a prosperous land in the center of Hangzhou city. Using the top-down construction method, the excavation depth of the foundation pit reached $23.0 \mathrm{~m}$. The method to control the deformation of the project could be available for reference for similar projects of the same type.

\section{Project and Environmental Conditions}

2.1. Project Description. This project was located in the Wulin Square of Hangzhou. It was a three-storey underground building with no ground buildings. The main structure of the underground mall was about $190 \mathrm{~m}$ long in the north-south direction and $220 \mathrm{~m}$ long in the east-west direction, with the area of $36794.5 \mathrm{~m}^{2}$. The excavation depth reached $23.0 \mathrm{~m}$, and the excavation depth of the section of Line 3 reached $27.0 \mathrm{~m}$. There was a deep and weak soil layer within the excavation area, and it ranged between $5.3 \mathrm{~m}$ and $22.7 \mathrm{~m}$ below the ground.

The north side of the project was only $17.0 \mathrm{~m}$ away from Zhejiang Exhibition Hall, and the east side was only $30.1 \mathrm{~m}$ away from Zhejiang Telecom Company; the south side was Stadium Road; the northeast corner was the subway station Wulin Square Station. The Metro Line 1 was built, and the tunnel section of Metro Line 3 was constructed with the project.

The project was divided into two small foundation pits by Metro Line 1 . The monitoring value of horizontal deformation could be used to explore the control effect of dividing a large foundation pit. During the implementation of the project, there were a large excavation and four vertical excavations in the western zone of Metro Line 1 . So the excavation speed was relatively fast, and the support can be formed quickly. The influence of the excavation exposure time on the deformation of the foundation pit could be studied by comparing the deformation of the monitoring points on the east, west, and north sides of the foundation pit.

2.2. Engineering Geological Conditions. As shown in Figure 1, the embedment depth and representative soil properties of typical soil profiles in different soil layers were plotted, including the maximum, minimum, and average values of geotechnical parameters. Note that $\mathrm{Es}_{0.1-0.2}$ was defined as the ratio of stress change to strain change when the stress increases from $0.1 \mathrm{MPa}$ to $0.2 \mathrm{MPa}$ in a one-dimensional compression test. The soil at the excavation depth was mainly composed of clay and silty clay, which was weak.

2.3. Design and Construction. The diaphragm wall of the foundation pit of this project was $1200 \mathrm{~mm}$ thick. The horizontal support system was dominated by structural floor slabs, and the three underground floors were designed with temporary diagonal bracing due to the storey height. The thickness of the roof slab was $500 \mathrm{~mm}$. The thickness was $300 \mathrm{~mm}$ for the B1 and B2 floor slabs, and it was $1200 \mathrm{~mm}$ thick for the bottom slabs. The cushion layer was $250 \mathrm{~mm}$. The diagonal brace was supported by $\varphi 609-16$ steel, supported on the corbel or pile cap, and the diagonal brace was supported on the bottom plate at a distance of $5.5 \mathrm{~m}$ from the diaphragm wall. The temporary diagonal brace layout is shown in Figure 2(a).

In order to control the deformation of the diaphragm wall of the foundation pit, a large-scale foundation reinforcement was carried out at the bottom of the pit which is shown by Figure 2(b). As shown in Figure 3, the foundation pit was divided into 4 zones.

At the beginning of the project, there were no significant problems in the construction according to the above construction plan, but when the construction reached the three-storey underground floor in Zone A, it was found that the diagonal brace needed about 40 days to reach the design strength level. On the contrary, due to the dense arrangement of diagonal braces, the construction work surface was difficult to expand after the diagonal braces were supported; the excavation efficiency was low. After the test construction in Zone A, the support plan was reviewed and discussed by experts. After the discussion, experts suggested to cancel the diagonal brace and thicken the cushion layer to $300 \mathrm{~mm}$.

Table 1 shows the schedule of the main construction procedures of the project.

2.4. Built Environment. As shown in Figure 3, the surrounding environment of the project was complex and many buildings were affected by excavation. The Zhejiang Exhibition Hall was located to the north of the project, Hangzhou Tower and Hangzhou Theatre were located to the west, Stadium Road was located to the south, and the Zhejiang Association for Science and Technology Building and Zhejiang Telecom Company were located to the east. The southwest and southeast corners were crossing passages, and the northeast corner was the Wulin Square Station of Metro Line 1; the distance of these buildings away from the excavation ranges from $17.0 \mathrm{~m}$ to $33.2 \mathrm{~m}$. The Zhejiang Exhibition Hall and the crossing passage were shallow foundations, and the rest of the buildings were pile foundations.

2.5. Engineering Monitoring. In order to comprehensively and systematically monitor the deformation and stress changes of the project during the construction period, the project has established a number of monitoring contents. The layout of monitoring points is shown in Figure 3. And, there were 21 inclinometer pipes for ground wall inclinometer monitoring, 15 inclinometer pipes for soil inclinometer monitoring outside the wall, 63 measuring points for ground settlement monitoring, 114 settlement observations for surrounding buildings, and 10 holes for groundwater level observation. Third-party monitoring would be monitored at a frequency of once every three 

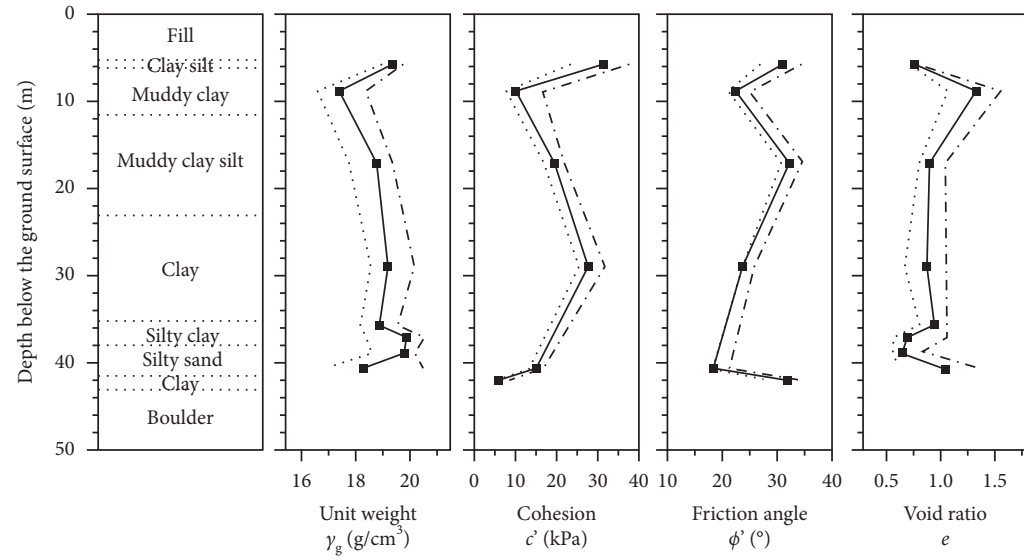

$$
\begin{aligned}
& \ldots . . \text { Minimum } \\
& .-\cdot-\text { Maximum } \\
& \rightarrow-\text { Average }
\end{aligned}
$$

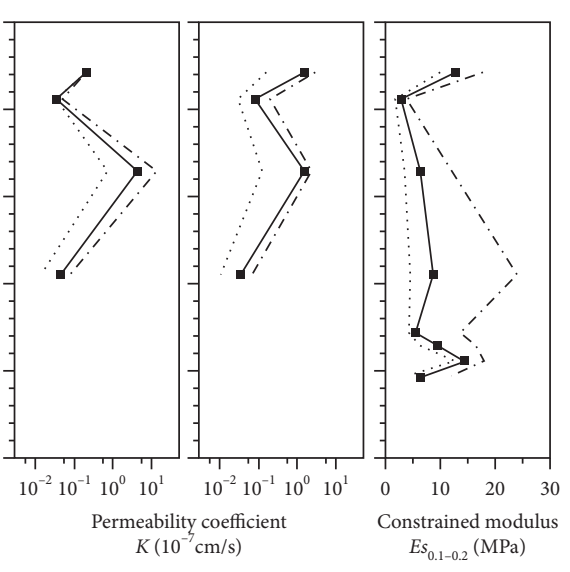

FIGURE 1: Soil profile and typical soil properties of the construction site.

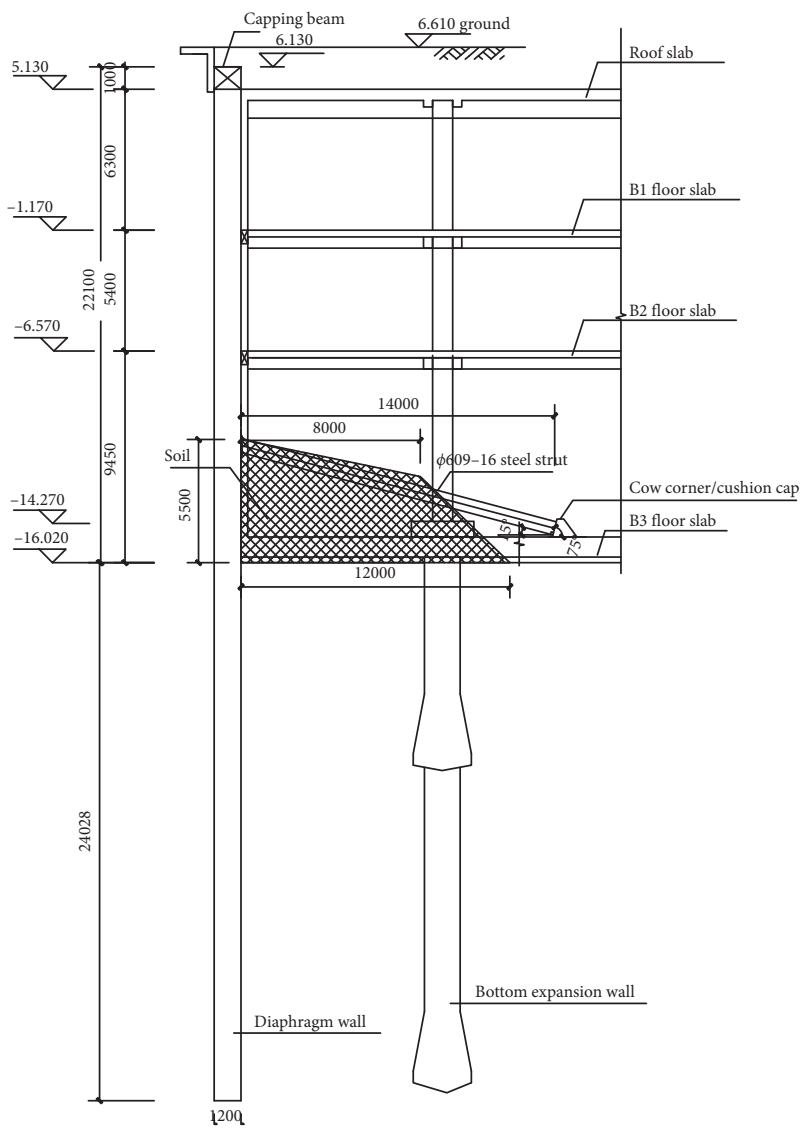

(a)

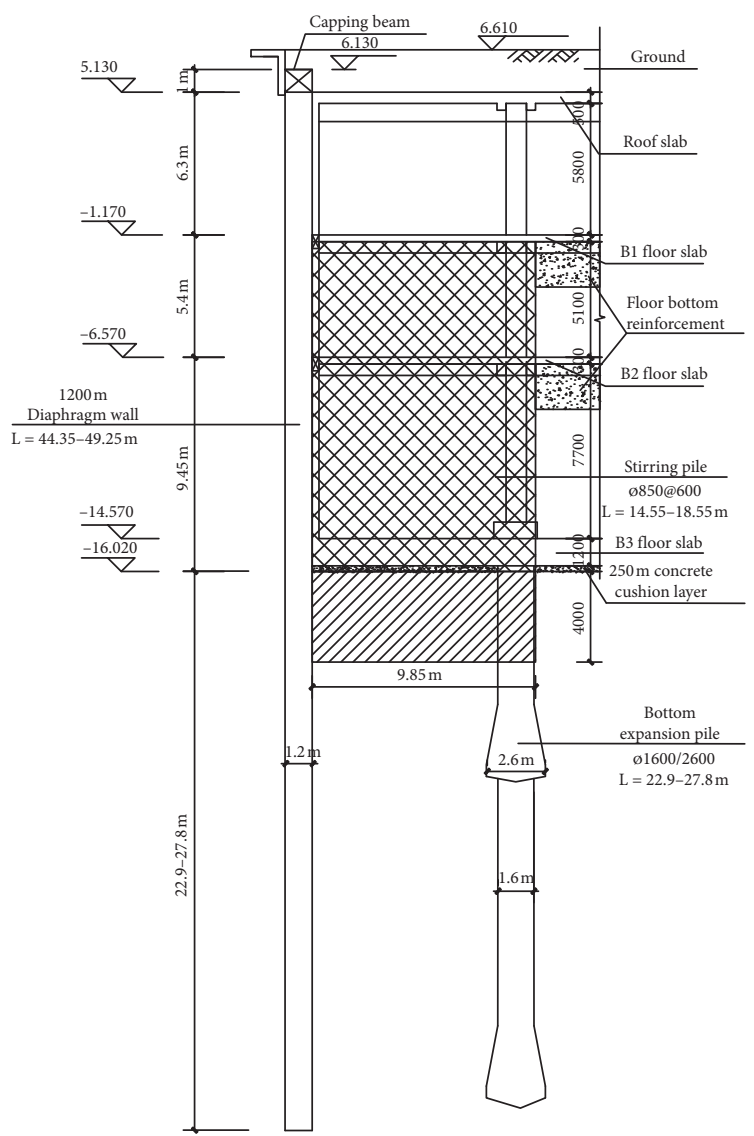

(b)

Figure 2: Typical cross of the excavation. (a) The south side of the excavation. (b) The north side of the excavation.

days and would be intensively monitored during peak construction periods and when monitoring was abnormal. The data in this paper was mainly based on third-party monitoring, and construction monitoring data was referred to during peak construction.

\section{Field Measurements}

3.1. Lateral Displacement of Diaphragm Wall. As shown in Figure 4(a), the measurement point with the largest deformation among the measurement points on each side of 


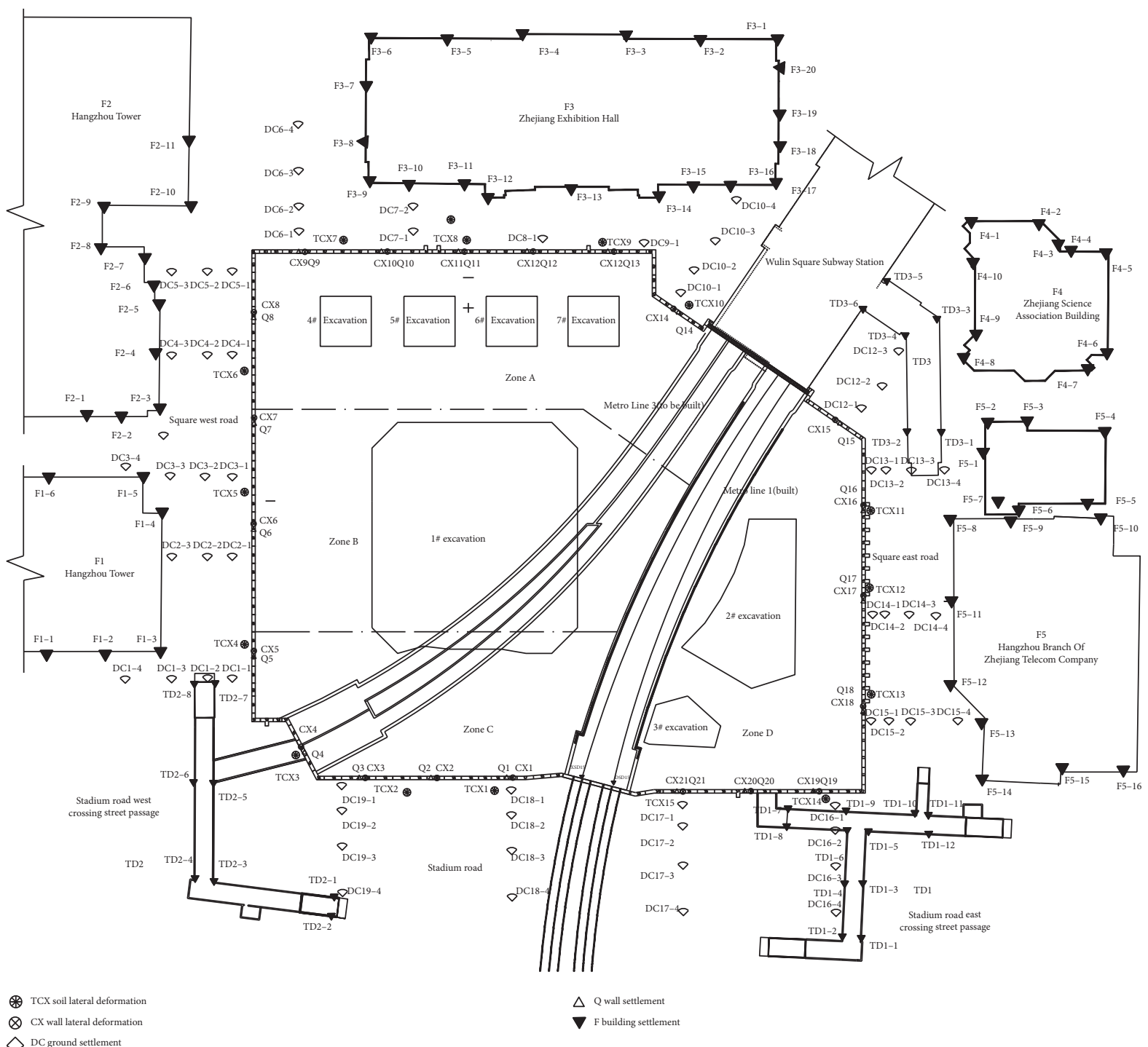

Figure 3: Layout of excavation and monitoring points.

TABLE 1: Construction schedule of the project.

\begin{tabular}{|c|c|c|c|c|c|}
\hline \multirow{2}{*}{ Stage } & \multirow{2}{*}{ Construction activity } & \multicolumn{4}{|c|}{ Period (day/month/year) } \\
\hline & & Zone A & Zone B & Zone C & Zone D \\
\hline 1 & Construction of diaphragm wall & \multicolumn{4}{|c|}{$1 / 8 / 2013-10 / 2 / 2014$} \\
\hline 2 & Construction of pile foundation & \multicolumn{4}{|c|}{$31 / 1 / 2014-15 / 7 / 2014$} \\
\hline 3 & $\begin{array}{l}\text { Excavation to } 2.3 \mathrm{~m} \text { below the ground and } \\
\text { construction of roof slabs }\end{array}$ & \multicolumn{4}{|c|}{$5 / 6 / 2014-20 / 1 / 2015$} \\
\hline 4 & Excavation to $7.7 \mathrm{~m}$ below the ground & $\begin{array}{c}20 / 1 / 2015-5 / 4 / \\
2015\end{array}$ & $\begin{array}{l}20 / 1 / 2015-26 / 4 / \\
2015\end{array}$ & $\begin{array}{c}20 / 1 / 2015-20 / 4 / \\
2015\end{array}$ & $\begin{array}{l}20 / 1 / 2015-25 / 4 / \\
2015\end{array}$ \\
\hline 5 & Construction of $\mathrm{B} 1$ floor slabs & $\begin{array}{c}13 / 3 / 2015-24 / 4 / \\
2015\end{array}$ & $\begin{array}{c}1 / 4 / 2015-15 / 5 / \\
2015\end{array}$ & $\begin{array}{c}11 / 4 / 2015-17 / 5 / \\
2015\end{array}$ & $\begin{array}{l}3 / 4 / 2015-14 / 5 / \\
2015\end{array}$ \\
\hline 6 & Excavation to $13.2 \mathrm{~m}$ below the ground & $\begin{array}{c}2 / 4 / 2015-15 / 5 / \\
2015\end{array}$ & $\begin{array}{c}17 / 5 / 2015-15 / 6 / \\
2015\end{array}$ & $\begin{array}{l}2 / 5 / 2015-20 / 6 / \\
2015\end{array}$ & $\begin{array}{l}25 / 4 / 2015-9 / 6 / \\
2015\end{array}$ \\
\hline 7 & Construction of B2 floor slabs & $\begin{array}{c}3 / 5 / 2015-3 / 6 / \\
2015\end{array}$ & $\begin{array}{c}\text { 9/6/2015-3/7/ } \\
2015\end{array}$ & $\begin{array}{c}28 / 5 / 2015-6 / 7 / \\
2015\end{array}$ & $\begin{array}{c}31 / 5 / 2015-27 / 6 / \\
2015\end{array}$ \\
\hline 8 & Excavation to $22.6 \mathrm{~m}$ below the ground & $\begin{array}{c}22 / 5 / 2015-16 / 7 / \\
2015\end{array}$ & $\begin{array}{l}3 / 7 / 2015-4 / 8 / \\
2015\end{array}$ & $\begin{array}{c}10 / 6 / 2015-28 / 8 / \\
2015\end{array}$ & $\begin{array}{l}13 / 6 / 2015-18 / 8 / \\
2015\end{array}$ \\
\hline 9 & Construction of B3 floor slabs & $\begin{array}{l}3 / 7 / 2015-8 / 9 / \\
2015\end{array}$ & $\begin{array}{c}23 / 7 / 2015-15 / 8 / \\
2015\end{array}$ & $\begin{array}{c}12 / 8 / 2015-10 / 9 / \\
2015\end{array}$ & $\begin{array}{l}\text { 9/7/2015-23/8/ } \\
2015\end{array}$ \\
\hline 10 & Construction of the slabs of excavation & \multicolumn{4}{|c|}{ 28/8/2015-15/11/2015 } \\
\hline
\end{tabular}



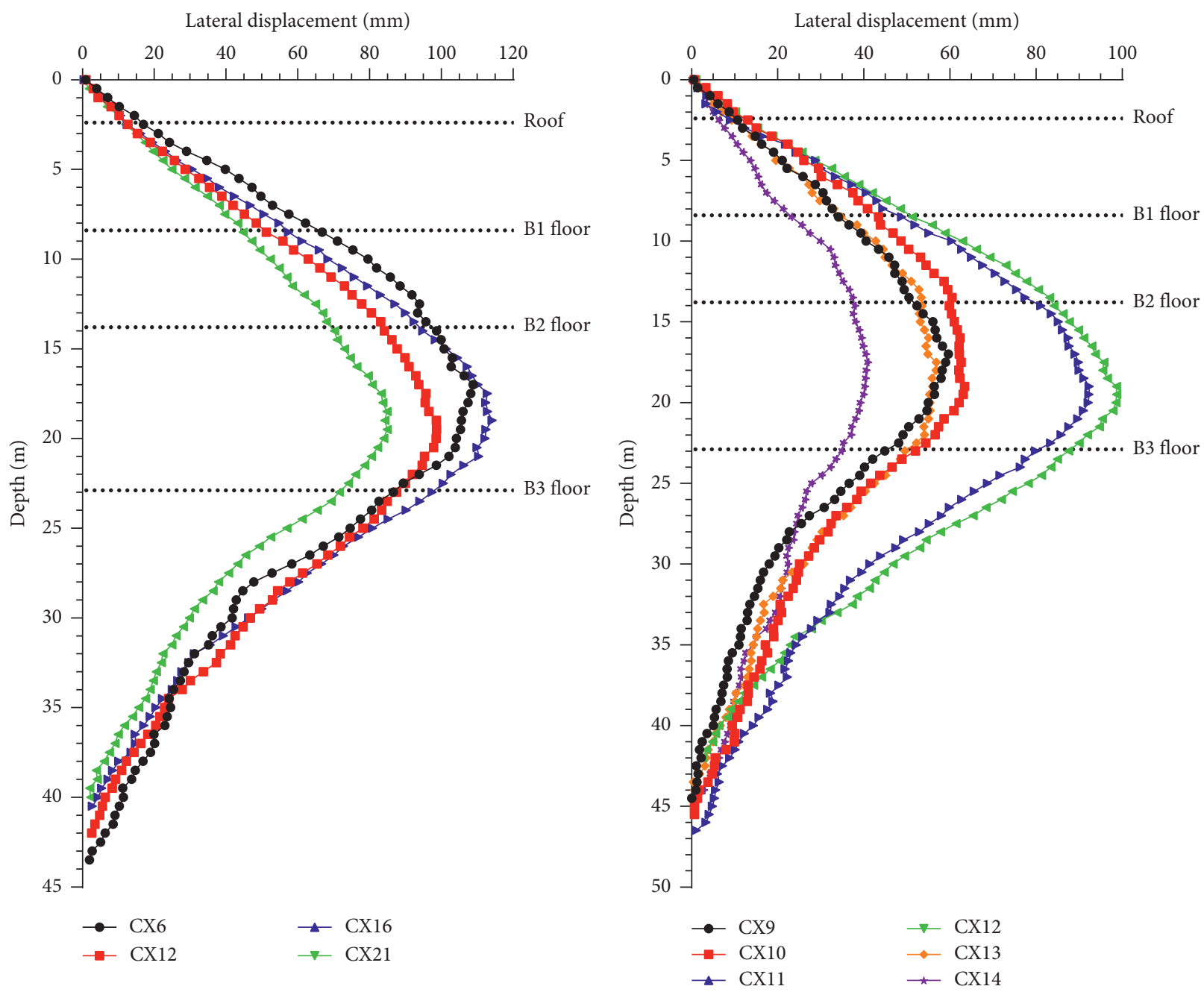

(a)

(b)

Figure 4: Continued. 


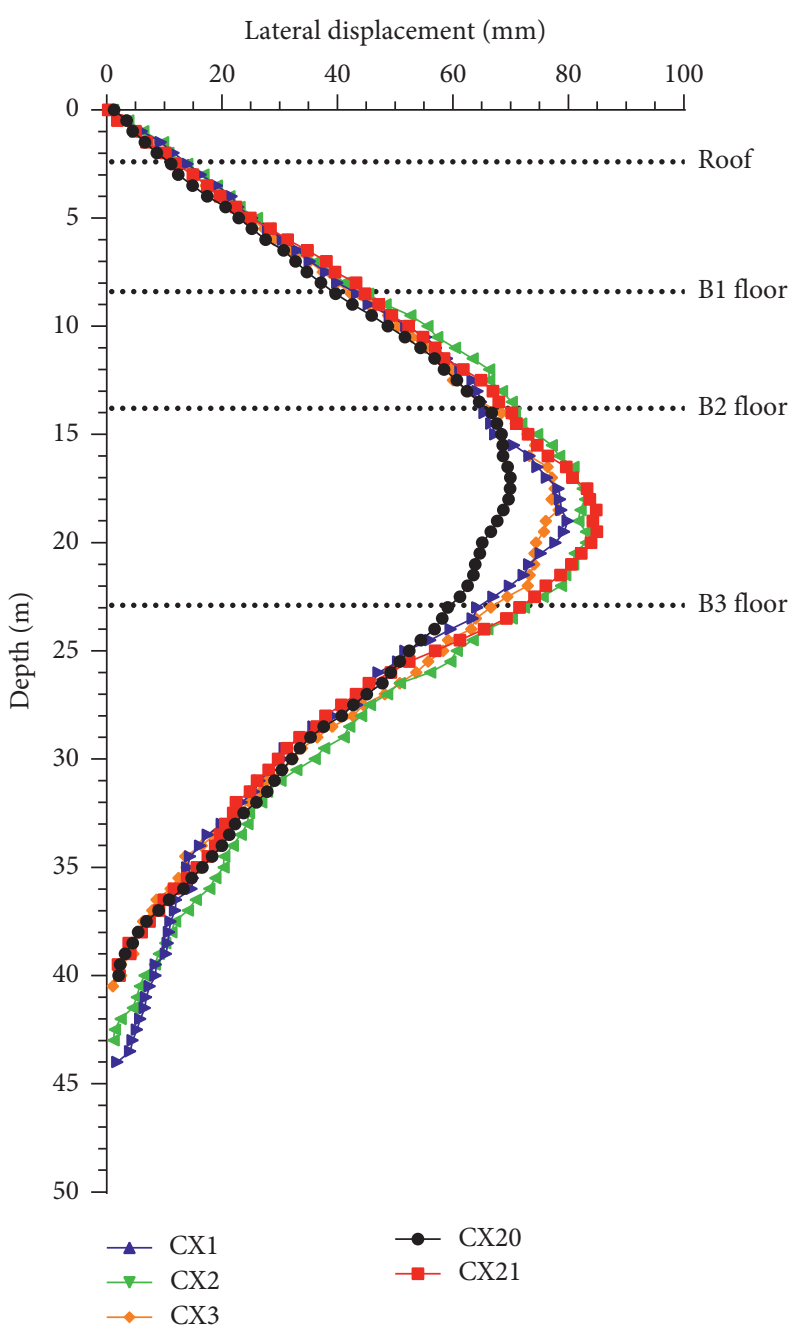

(c)

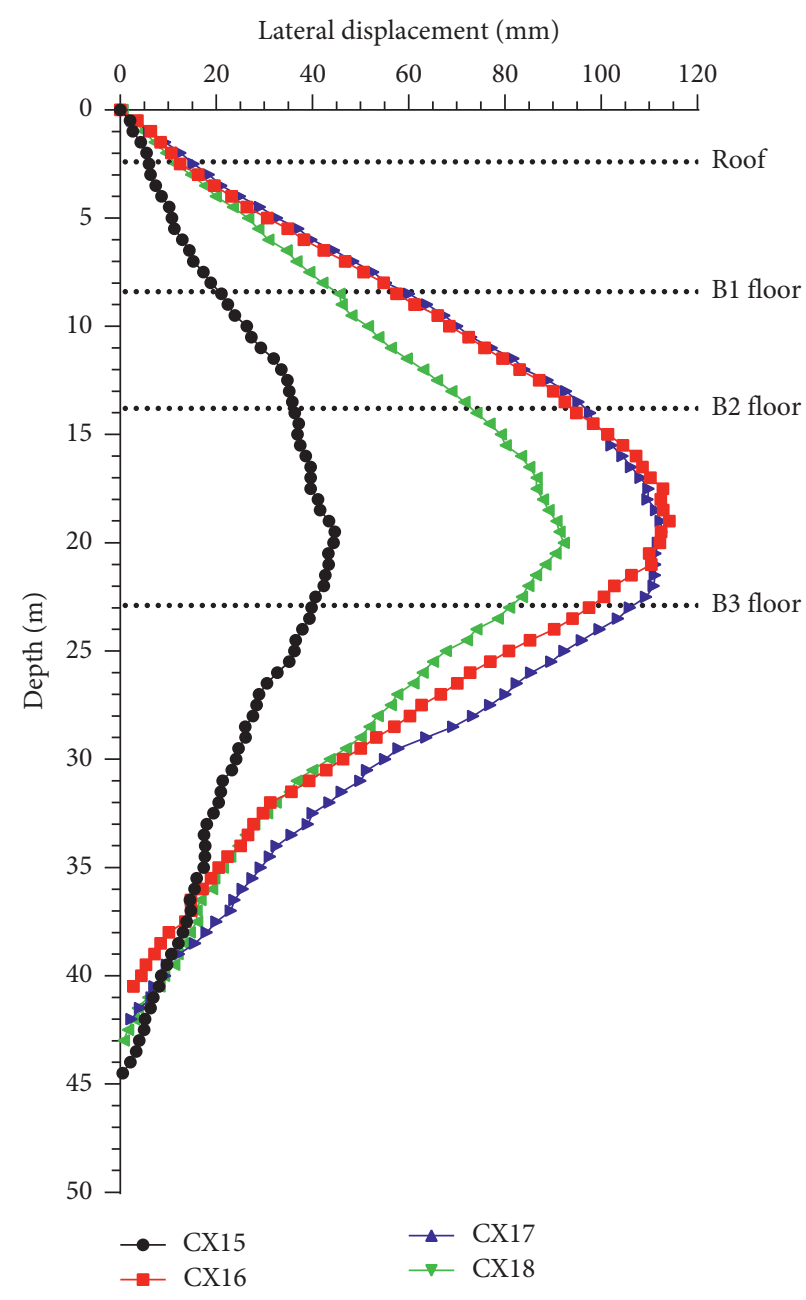

(d)

Figure 4: Lateral displacement of the excavation. (a) The maximum deformation monitoring points of each side. (b) The north side of the excavation. (c) The south side of the excavation. (d) The east side of the excavation.

the diaphragm wall was selected as a typical representative. The selected monitoring point was basically near the midpoint of each side of the foundation pit. CX6 was the measurement point on the west side of the foundation pit, CX12 was the northern measurement point, CX16 was the eastern measurement point, and CX21 was the southeast measurement point. The final horizontal displacement state of each measurement point is shown in Figures 5 and 6. The lateral displacement of CX16 was the largest, reaching $114.19 \mathrm{~mm}$.

It could be seen from Figure 4(a) that the lateral displacement deformation of the diaphragm wall was similar to the "saddle shape." The maximum lateral displacement position was $18.5-19 \mathrm{~m}$.

For the convenience of comparison, the maximum lateral displacement value of CX16 was used as the reference value. The maximum lateral displacement of CX6 was $95.33 \%$ of CX16. The lateral displacement of CX12 was $98.69 \mathrm{~mm}$, which was $86.43 \%$ of CX16. The maximum lateral displacement of CX21 in the southeast of the foundation pit was $84.93 \mathrm{~mm}$, which was $74.38 \%$ of CX16 horizontal displacement.

As shown in Figure 4(b), CX11 and CX12 measuring points had the largest lateral displacement. The measuring points CX9, CX10, and CX13 were relatively close to the diaphragm wall on the west or east side of the project. The lateral stiffness provided by the diaphragm wall at the corner assisted to control the deformation.

Figure 4(c) is the lateral displacement of the north side diaphragm wall. The lateral displacement of the diaphragm wall on the south side was relatively balanced, and there was no significant maximum deformation measuring point.

The deformation characteristic on the east and west sides was similar, so just selected the east side as Figure 4(d). CX19 measuring point on the east side was damaged during the project implementation, so there were only 4 measuring points on the east side. Although the maximum lateral displacements on the east and west sides were close, the difference was only $4.67 \%$, but there is a significant difference in the horizontal displacement distribution along the 


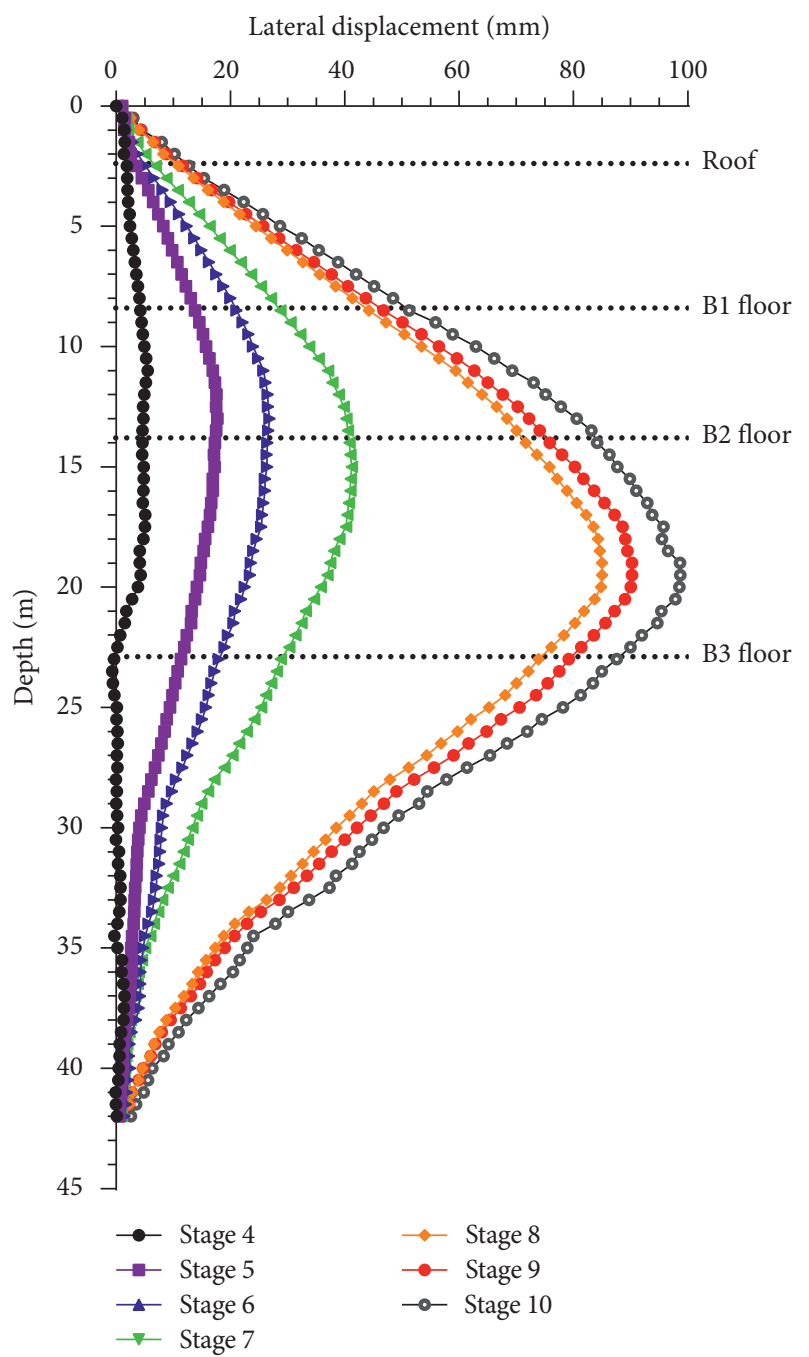

(a)

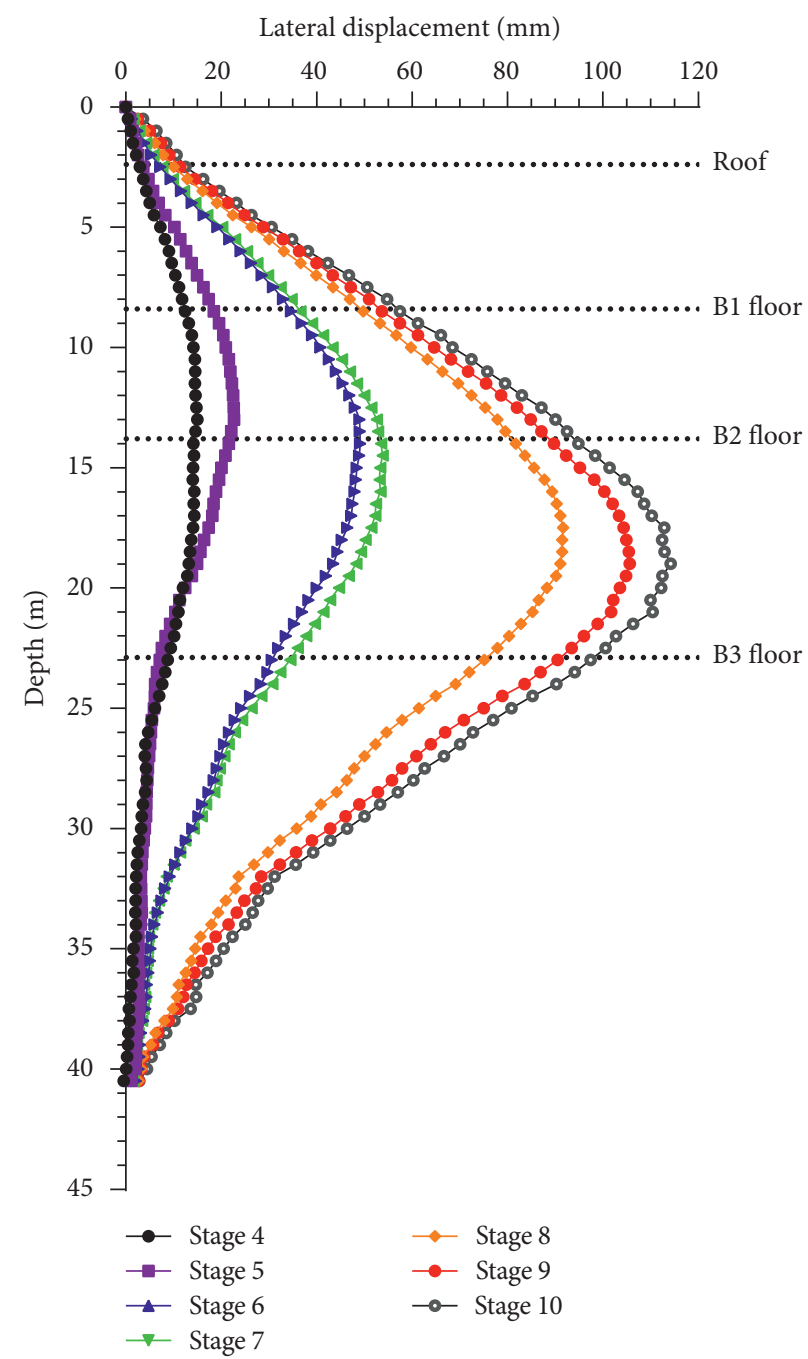

(b)

FIgURE 5: Lateral displacement of each stage. (a) CX12. (b) CX16.

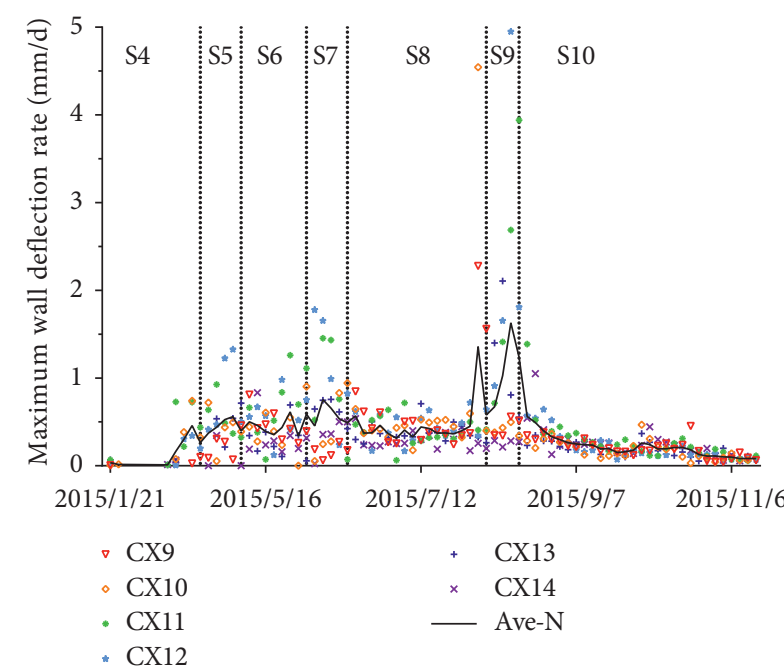

(a)

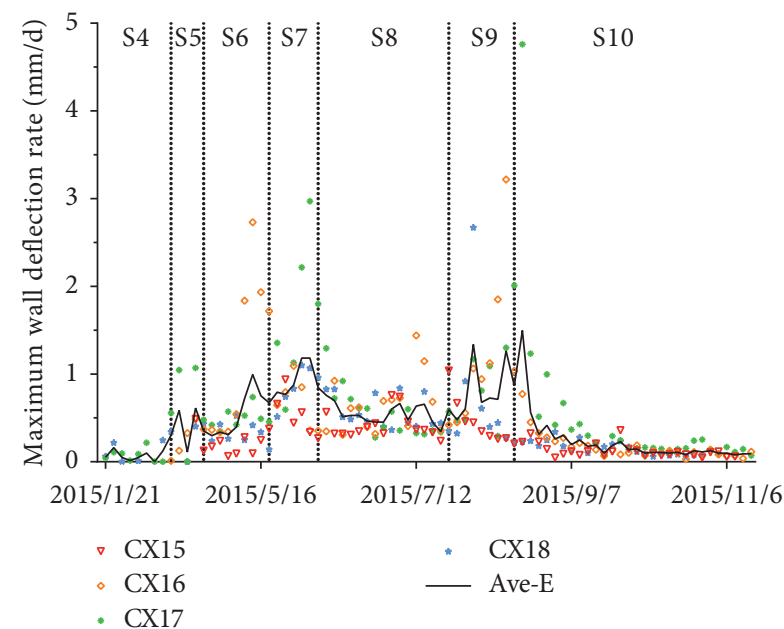

(b)

Figure 6: Maximum wall deformation rate over time. (a) CX12. (b) CX16. 
side of the foundation pit. The maximum lateral displacement on the east side was larger. The maximum lateral displacements of CX16 and CX17 were very close, indicating that at least $30 \mathrm{~m}$ of the diaphragm wall in the east side had reached a large lateral displacement.

Figure 7 is the stage incremental diagram of the lateral displacement of the typical measurement points of the diaphragm wall. It could be seen that the lateral displacement of stage 8 was significantly greater than the other stage and ranged from $27.71 \%$ to $46.13 \%$ of the total displacement.

Since the exposure duration of CX16 in stage 6 was much longer than the other monitoring points, the incremental deformation of CX16 reached $23.12 \%$ of the total deformation, which was significantly higher than other monitoring points. The CX6 monitoring point in stage 7 had a large deformation due to the long exposure time of the excavation. Various construction methods should be used to shorten the exposure duration especially excavating deep soil layers, and it could contribute to controlling the deformation of the diaphragm wall.

Figure 5 is a diagram of the lateral displacement of the diaphragm wall under various working conditions. It was easy to know that the stage 8 , which was the three-storey underground excavation stage, was the stage with the largest lateral displacement increment, which was significantly larger than the other stage.

Since the excavation depth of the three underground floors of this project was $9.1 \mathrm{~m}$, the excavation depth was large and deep, so the diaphragm wall had a large deformation in the stage 8 . As the excavation depth gradually increased, the location of the maximum deformation of the diaphragm wall also gradually moved downward.

Comparing Figures 5(a) and 5(b), the exposure duration of CX16 in stage 6 was much longer than the other monitoring points, resulting in large deformation. And, the deformation of the stage 6 reached $29.2 \%$ of the total deformation and was significantly greater than any other points. The deformation distribution of other monitoring points was similar to that of CX12.

Figure 6 shows the distribution of diaphragm wall lateral displacement rates during the project period. Figure 6(a) shows the north side, and Figure 6(b) shows the east side. There was a significant deformation rate peak on the north side, which was the stage 9 that was the B3 slab construction stage. The maximum deformation rate was $4.95 \mathrm{~mm} / \mathrm{d}$, the maximum average deformation rate was $1.63 \mathrm{~mm} / \mathrm{d}$, and the deformation rate remained below $0.5 \mathrm{~mm} / \mathrm{d}$ at other times. There were multiple peaks in the east side; each excavation would cause large wall deformation; the maximum deformation rate was $4.76 \mathrm{~mm} / \mathrm{d}$; the maximum average rate was $1.49 \mathrm{~mm} / \mathrm{d}$, but there were multiple peak deformation rates over $0.8 \mathrm{~mm} / \mathrm{d}$.

Figure 8(a) shows the relationship of the maximum lateral displacement of the diaphragm wall and excavation depth. Figure 8(b) shows the relationship of the location of maximum lateral displacement and excavation depth. The zone division is shown in Figure 3. $H_{e}$ represents the excavation depth of the foundation pit, $H_{m}$ represents the depth of the maximum lateral displacement, and $\delta_{\mathrm{hm}}$ represents the maximum lateral displacement of the diaphragm wall. The lines Ave-S5, Ave-S7, and Ave-S10 in the figure represent the average value of the lateral displacement of all the diaphragm walls in the corresponding stage, and the Min and Max lines were the envelope lines of the lateral displacement of the diaphragm walls.

It could be seen that, as the excavation depth gradually increased, the lateral displacement of the diaphragm wall gradually increased. When the excavation reached the bottom of the pit, the average value of the maximum lateral displacement of the diaphragm wall reached $0.30 \% H_{e}$. The maximum deformation point of the foundation pit was CX16 in the middle of the east side. And, its maximum lateral displacement was $0.50 \% \mathrm{H}_{e}$; the minimum deformation point was CX4 which was the southwest of the excavation, and the maximum lateral displacement was $0.14 \% H_{e}$. Zone $\mathrm{D}$ was the east side of the foundation pit, and the lateral displacement of Zone D was larger than the other sides.

With the increasing of the excavation depth, the maximum lateral displacement depth of the diaphragm wall was gradually increasing. The average depth of maximum lateral displacement of the wall under the stage 5 , stage 7 , and stage 10 separately was $12.04 \mathrm{~m}, 13.35 \mathrm{~m}$, and $18.33 \mathrm{~m}$. The maximum lateral deformation depths separately were $13.50 \mathrm{~m}, 14.38 \mathrm{~m}$, and $19.50 \mathrm{~m}$ compared with Zone D. The maximum lateral displacement depths of other zones were close to the average value, indicating that the slower excavation and support in Zone $\mathrm{D}$ made the maximum lateral displacement point of the diaphragm wall move down.

3.2. Settlement of Diaphragm Wall. Figure 9 shows the settlement of the top of the diaphragm wall. Most of monitoring points bulged upward in stage 4, indicating that the rebound of the deep stratum caused by the excavation and unloading of the shallow layers puts the upward stress on the diaphragm wall and causes it to move upward. With the continuous increasing of the excavation depth, the top of the diaphragm wall gradually transformed into settlement. The settlement in the midspan area was the largest, which also indicated that the settlement of the diaphragm wall was mainly due to excessive lateral displacement.

3.3. Ground Surface Settlement. The surface settlement on the north and east sides of the foundation pit is shown in Figures 10(a) and 10(b). The maximum settlement point in the northern side of the foundation pit was DC7-1, with a maximum settlement of $71.93 \mathrm{~mm}$. There were several monitoring points on the east side of the foundation pit that had reached $80 \mathrm{~mm}$, and the maximum settlement was $86.75 \mathrm{~mm}$. Compared with the ratio of the lateral displacement of each other, the ratio of surface settlement had increased.

The rapid settlement period of the surface lagged behind the rapid development period of lateral displacement of the diaphragm wall. The lateral displacement rate of the diaphragm wall dropped quickly after stage 9, while the surface settlement generally entered the rapid settlement period in 


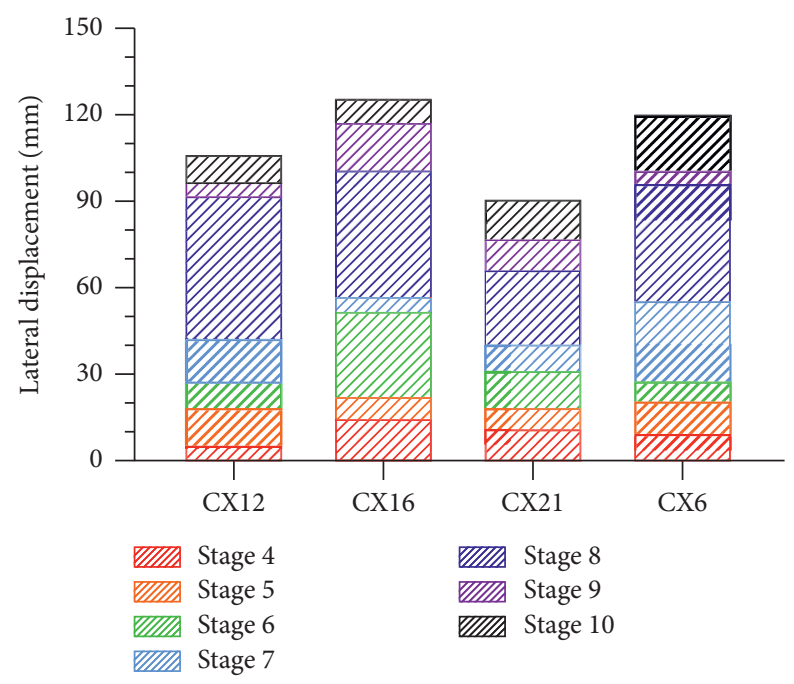

Figure 7: Lateral displacement increment of the maximum deformation monitoring points of each side.

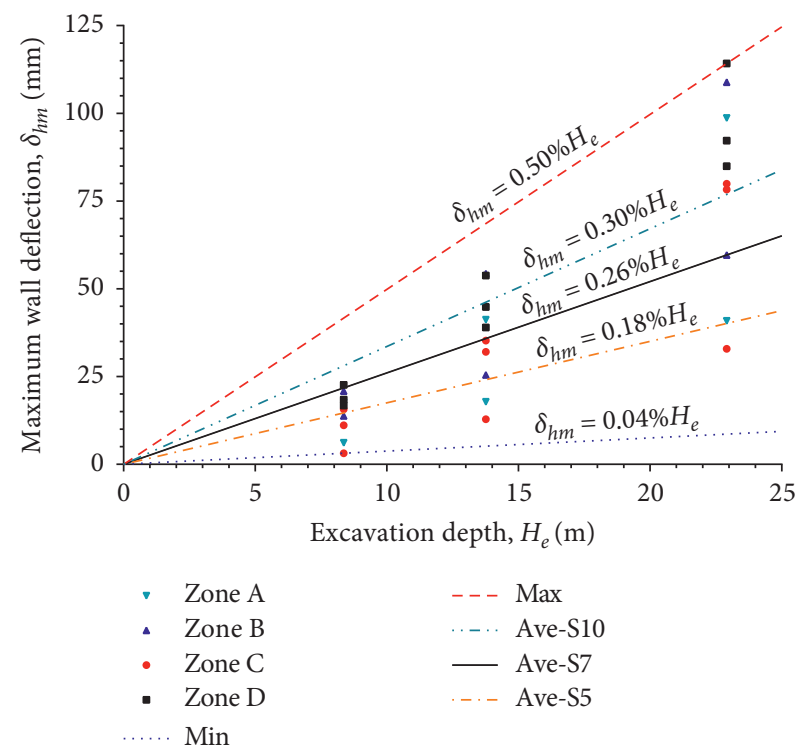

(a)

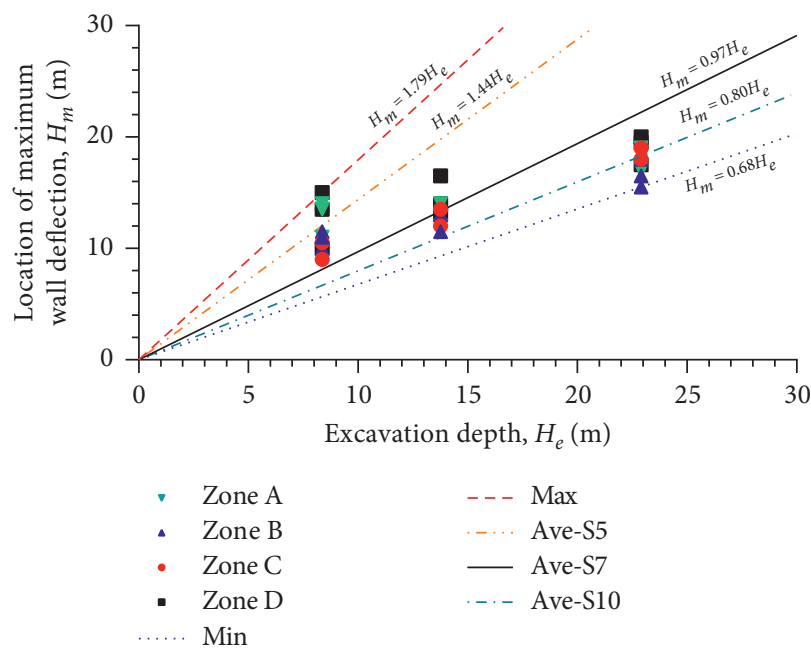

(b)

FIGURE 8: Relationship between (a) maximum wall deformation and excavation depth and (b) location of maximum wall deformation and excavation depth.

the late stage 9 and kept the rate about one month, and there was no significant settlement rate convergence in stage 10 .

Figure 11 shows the relationship between the maximum lateral displacement of the diaphragm wall and the corresponding maximum settlement of the ground surface. The average value of the ratio of surface settlement to lateral displacement of the foundation pit was 0.82 . The surface settlement in Zone C was all arranged on the Stadium Road on the south side, and the traffic flow was much larger than other roads around the project. Therefore, the ratio of surface settlement to lateral displacement in Zone C was larger than others, reaching 0.90 . Therefore, in addition to the positive correlation between the surface settlement and the lateral displacement of the adjacent diaphragm wall, it was also related to the traffic load nearby.

3.4. Settlement of Buildings. Figures 12(a) and 12(b) are the time history curves of the settlement monitoring points of the buildings on the north and south sides of the Zhejiang Exhibition Hall. F3-12, F3-13, and F3-14 were arranged on the south steps of the exhibition hall, and the remaining monitoring points were arranged on the wall of the exhibition hall. The monitoring data could not be updated after the remaining monitoring points were scrapped during the later wall decoration of the exhibition hall. The monitoring 


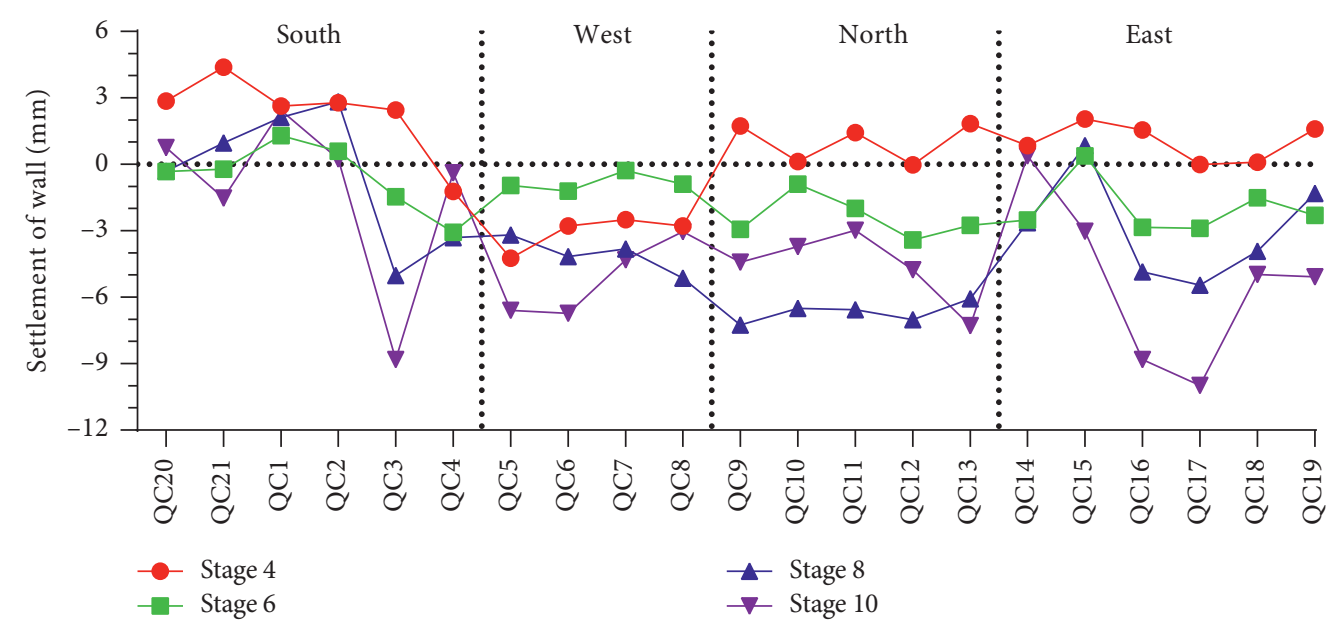

Figure 9: Settlement of walls.

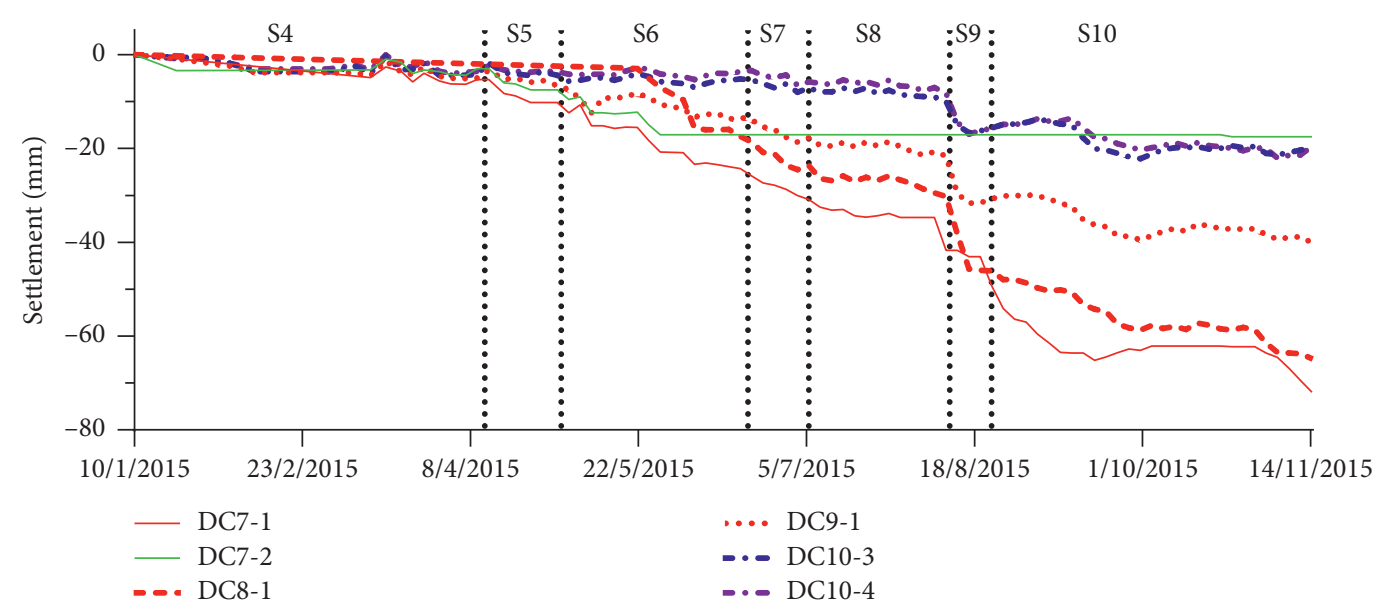

(a)

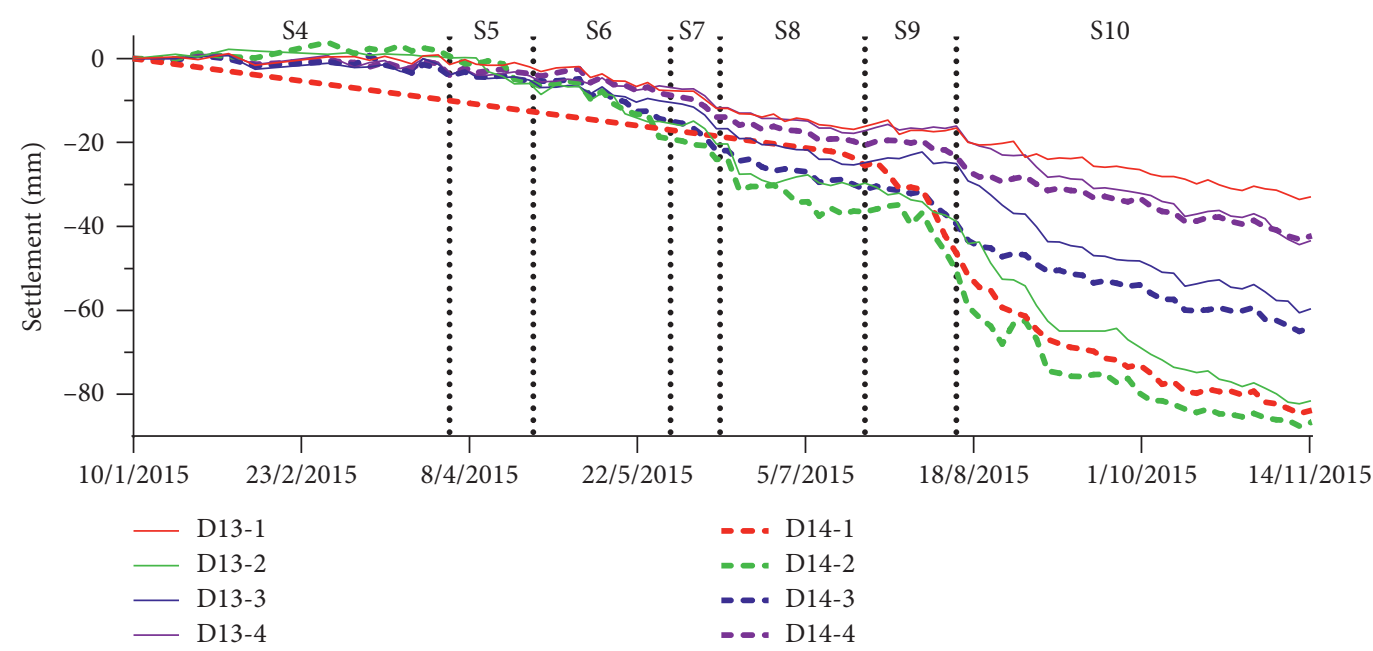

(b)

Figure 10: Settlement of ground surface over time. (a) North side. (b) East side. 


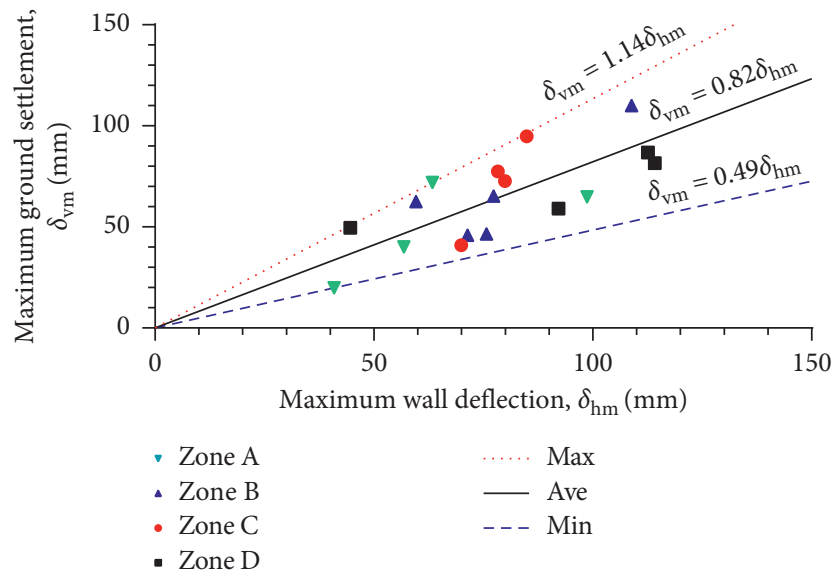

FIGURE 11: Relationship between maximum wall deflection and maximum ground settlement.

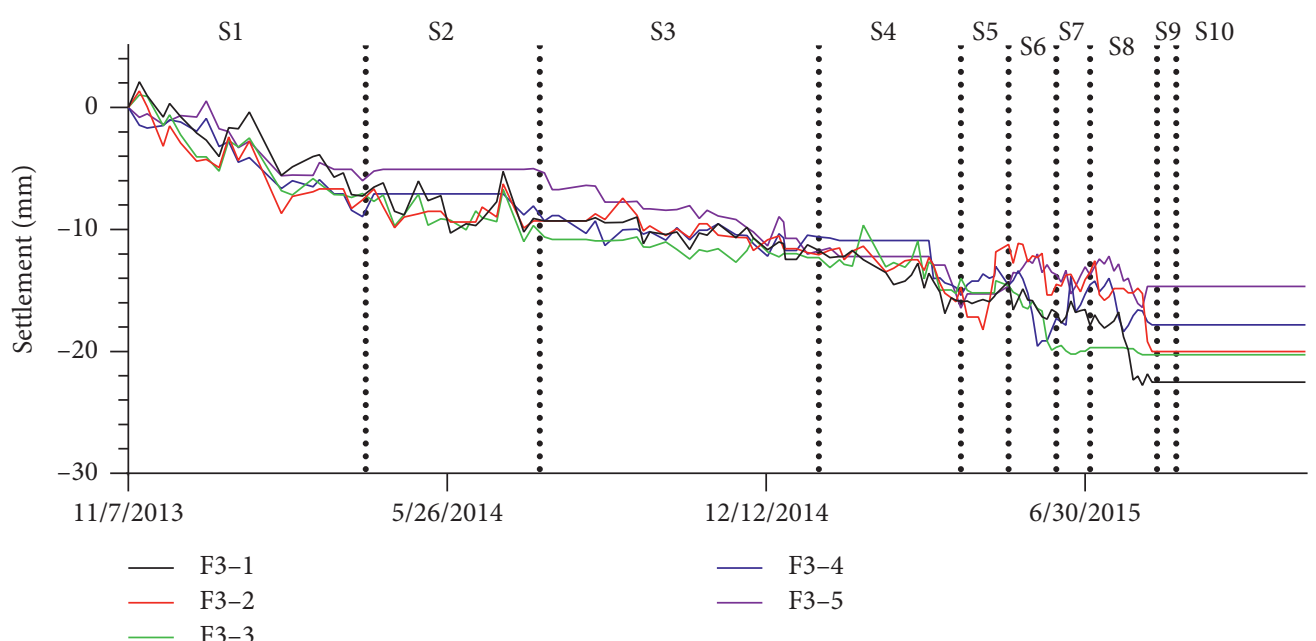

(a)

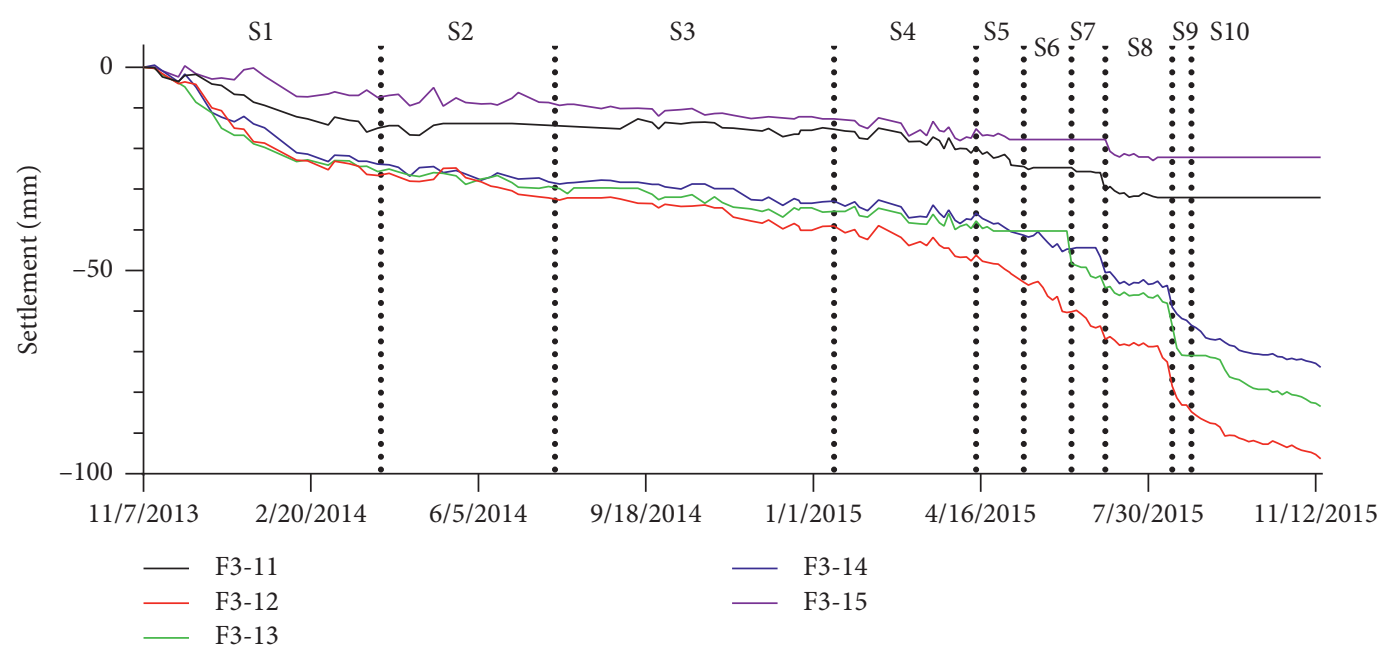

(b)

Figure 12: Continued. 


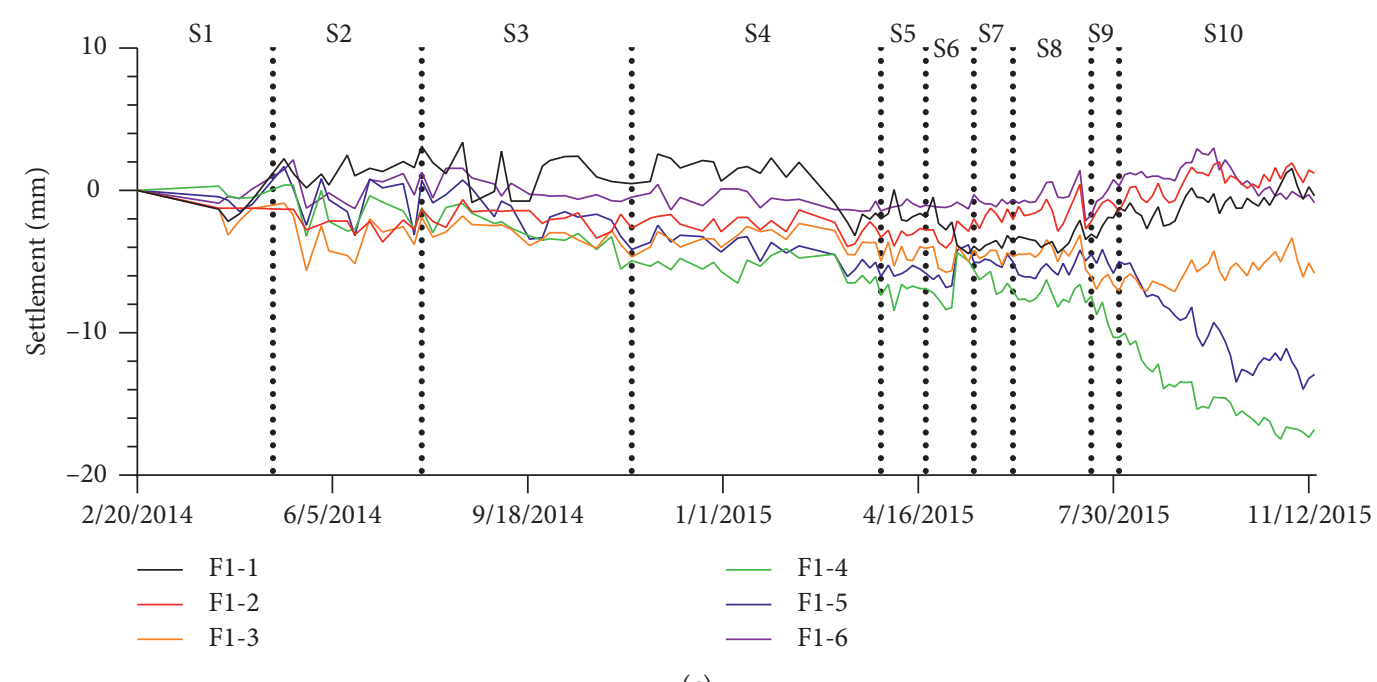

(c)

Figure 12: Settlement of nearby buildings. (a) North side of Zhejiang Exhibition Hall. (b) South side of Zhejiang Exhibition Hall. (c) Hangzhou Theatre.

points F3-12 to F3-14 were closest to the middle of the north side of the foundation pit and were set on the steps of the exhibition hall. And, other monitoring points were set on the wall of the exhibition hall.

It could be seen that the maximum settlement point on the north side of the exhibition hall was F3-1, the maximum settlement was $22.51 \mathrm{~mm}$, and the settlement of this monitoring point had reached $15.92 \mathrm{~mm}$ before stage 4 , and the stage of excavation did not cause the significant settlement of this monitoring point; the total settlement during stage 4 to stage 10 was $8.25 \mathrm{~mm}$. The conditions of the other observation points on the north side were similar.

The settlement of the monitoring point on the south side of Zhejiang Exhibition Hall had a greater correlation with the excavation of the foundation pit, especially F3-12, which was the closest to the largest lateral displacement area. The maximum settlement of F3-12 was $97.42 \mathrm{~mm}$. The settlement of F3-11 was significantly smaller than that of F3-12, only $32.09 \mathrm{~mm}$. As the foundation pit construction was completed, the exhibition hall was still undergoing reinforcement construction, and subsequent settlement values could not be collected.

The settlement of the steps was close to that of the ground surface, and the settlement of the outer wall was smaller, which represented the settlement of the main structure of the exhibition hall after reinforcement.

Figure 12(c) shows the settlement of Hangzhou Theatre. The F1-4 and F1-5 monitoring points of the Hangzhou Theatre were also arranged on the outdoor steps of the building. The settlement was larger than the other points, reaching $16.78 \mathrm{~mm}$. The settlements of F1-4 and F1-5 in the stage 10 were $38.49 \%$ and $61.34 \%$ of the total settlement, respectively, which were similar to the ground settlement characteristics around the foundation pit.

The Hangzhou Theatre was basically not affected by the excavation of the foundation pit, which showed that the frame structure of the pile foundation within about $30 \mathrm{~m}$ from the foundation pit will basically not caused harmful structural damage due to the excavation of the foundation pit. So the other buildings are not discussed in this paper.

3.5. Corresponding Deformation Analysis. The exhibition hall on the north side of the excavation was greatly affected by the excavation of the foundation pit, resulting in larger settlement. In order to study the deformation relationship between the exhibition hall, the monitoring point CX12, which was the largest deformation in the middle of the north side foundation pit, and other monitoring points that were closest to CX12 were selected, which includes the inclination of deep soil monitoring point TCX8, the surface settlement monitoring point DC8-1, and the building settlement monitoring points F33, F3-12, and F3-13.

Figure 13(a) is the deformation rate time history curve. It is shown that when the CX12 measuring point produced a larger deformation, other monitoring points would also have a corresponding larger deformation rate, and the deformation peaks were successively reached according to the distance from the CX12 monitoring point. The CX12 monitoring point was the cause of the deformation of other monitoring points, and its maximum deformation rate was $4.89 \mathrm{~mm} / \mathrm{d}$, and the maximum deformation rate of other measuring points was between 2.5 and $3.0 \mathrm{~mm} / \mathrm{d}$.

Figure $13(\mathrm{~b})$ is the violin-shaped deformation rate distribution curve. The deformation rate of CX12, except for the extreme point, was $4.89 \mathrm{~mm} / \mathrm{d}$, and the rate did not exceed $2 \mathrm{~mm}$ at other times, and the corresponding three-time rapid deformation distribution corresponded to three excavations. Other monitoring points also had significant rapid deformation periods, but the three excavation conditions could not be distinguished. 


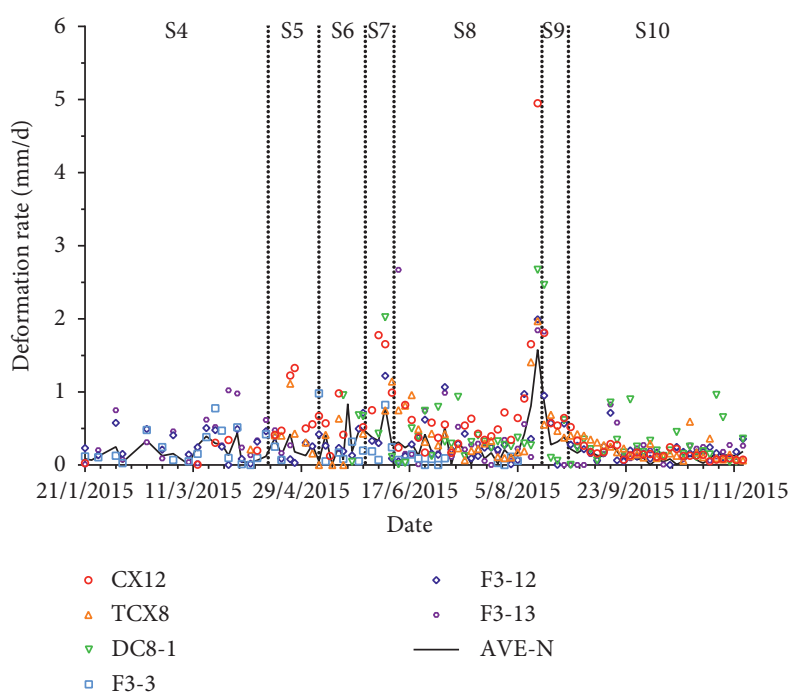

(a)

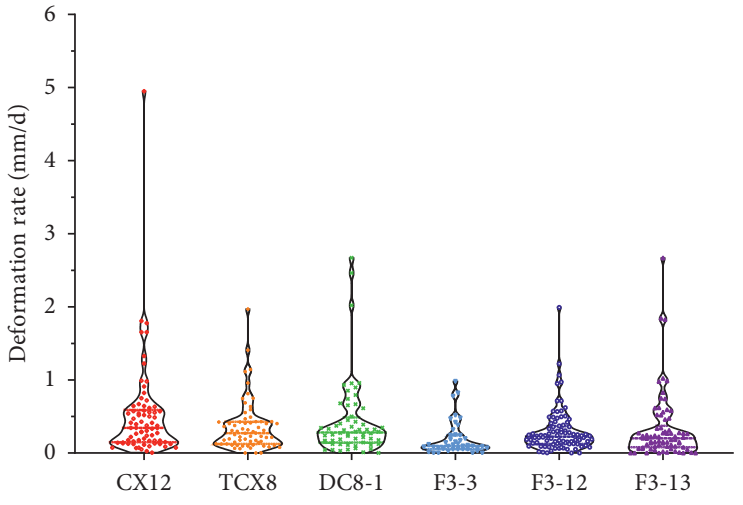

(b)

Figure 13: Deformation rate of the north side of the excavation. (a) Time history curve. (b) Violin distribution.

\section{Conclusions}

This paper introduces the deformation characteristics of the diaphragm wall and surrounding environment of the deep excavation using the top-down construction method in the soft clay area of Hangzhou. The following conclusions are drawn:

(1) The top-down construction method can effectively control the deformation of the deep excavation in the Hangzhou area. The maximum wall lateral displacement of this project was $114.19 \mathrm{~mm}$, and the maximum ground settlement was $110.02 \mathrm{~mm}$.

(2) The maximum lateral displacement of this project was $0.49 \% H_{e}$, and the maximum surface settlement of the excavation was $0.48 \% H_{e}$. There was a strong correlation between ground settlement and lateral displacement of the diaphragm wall.

(3) Factors such as zoned excavation, pit bottom support method, and excavation exposure time had a greater impact on the deformation characteristics of the diaphragm wall. The zoned excavation had the greatest impact, and the exposure time of the foundation pit had less impact

(4) The constructions around the foundation pit of this project had caused a certain amount of settlement due to the excavation of the foundation pit. The maximum settlement is $96.31 \mathrm{~mm}$ at the measuring point of the south-facing steps of the exhibition hall which was $17.0 \mathrm{~m}$ away from the excavation, but its main structure would not be affected after reinforcement; the maximum settlement during the excavation was only $17.12 \mathrm{~mm}$.

\section{Data Availability}

The data used to support the findings of this study are available from the corresponding author upon request.

\section{Conflicts of Interest}

The authors declare that they have no conflicts of interest regarding the publication of this paper.

\section{Acknowledgments}

This work was financially supported by the National Natural Science Foundation of China (no. 41672264).

\section{References}

[1] R. J. Finno, D. K. Atmatzidis, and S. B. Perkins, "Observed performance of a deep excavation in clay," Journal of Geotechnical Engineering, vol. 115, no. 8, pp. 1045-1064, 1989.

[2] P.-G. Hsieh and C.-Y. Ou, "Shape of ground surface settlement profiles caused by excavation," Canadian Geotechnical Journal, vol. 35, no. 6, pp. 1004-1017, 1998.

[3] G. T.-C. Kung, "Comparison of excavation-induced wall deflection using top-down and bottom-up construction methods in taipei silty clay," Computers and Geotechnics, vol. 36, no. 3, pp. 373-385, 2009.

[4] C.-Y. Ou, J.-T. Liao, and H.-D. Lin, "Performance of diaphragm wall constructed using top-down method," Journal of Geotechnical and Geoenvironmental Engineering, vol. 124, no. 9, pp. 798-808, 1998.

[5] G. W. Clough and T. D. O 'Rourke, "Construction induced movements of in situ walls,"vol. 25, pp. 439-470, in Proceedings of ASCE conference on design and performance of earth retaining structures, vol. 25, pp. 439-470, Geotechnical Special Publication, Ithaca, NY, USA, June 1990.

[6] C. Yoo, "Behavior of braced and anchored walls in soils overlying rock," Journal of Geotechnical and Geoenvironmental Engineering, vol. 127, no. 3, pp. 225-233, 2001.

[7] M. Long, "Database for retaining wall and ground movements due to deep excavations," Journal of Geotechnical and Geoenvironmental Engineering, vol. 127, no. 3, pp. 203-224, 2001.

[8] C. Y. Ou, P. G. Hsieh, and D. C. Chiou, "Characteristics of ground surface settlement during excavation," Canadian Geotechnical Journal, vol. 30, no. 5, pp. 758-767, 1993. 
[9] J. H. Wang, Z. H. Xu, and G. E. Di, "Performance of a deep excavation constructed using the united method: bottom-up method in the main building part and top-down method in the annex building part," in Proceedings of the GeoShanghai International Conference, pp. 385-392, Shanghai, China, June 2006.

[10] J. H. Wang, Z. H. Xu, and W. D. Wang, "Wall and ground movements due to deep excavations in Shanghai soft soils," Journal of Geotechnical and Geoenvironmental Engineering, vol. 136, no. 7, pp. 985-994, 2010.

[11] Y. Tan and D. Wang, "Characteristics of a large-scale deep foundation pit excavated by the central-island technique in Shanghai soft clay. I: bottom-up construction of the central cylindrical shaft," Journal of Geotechnical and Geoenvironmental Engineering, vol. 139, no. 11, pp. 1875-1893, 2013.

[12] Y. Tan and D. Wang, "Characteristics of a large-scale deep foundation pit excavated by the central-island technique in Shanghai soft clay. II: top-down construction of the peripheral rectangular pit," Journal of Geotechnical and Geoenvironmental Engineering, vol. 139, no. 11, pp. 1894-1910, 2013.

[13] H. Wu, Y. J. Zhong, W. Xu, W. Shi, X. Shi, and T. Liu, "Experimental investigation of ground and air temperature fields of a cold-region road tunnel in NW China," Advances in Civil Engineering, vol. 2020, Article ID 4732490, 13 pages, 2020.

[14] H. Li, E. L. Ma, J. X. Lai et al., “Tunnelling-induced settlement and treatment techniques for a loess metro in Xi'an," $A d$ vances in Civil Engineering, vol. 2020, Article ID 1854813, 20 pages, 2020. 